\title{
Projeto estratégico de ocupação do fundo de vale do córrego da Aldeia no perímetro urbano de Fernandópolis/SP
}

\author{
Strategic occupation project of the córrego da Aldeia's valley bottom in the \\ urban perimeter of Fernandópolis/SP
}

Ricardo Henrique Alves Corrêa, Gisele Herbst Vazquez, Luiz Sergio Vanzela

Universidade Brasil, Fernandópolis, SP, Brasil

\section{Resumo}

A política urbana induz o processo de ocupação dos fundos de vale sem respeitar a dinâmica natural desses locais, aplicando a legislação ambiental e os instrumentos urbanísticos de forma idêntica à zona rural. Além disso, é comum observar a desvalorização dessas áreas para o mercado imobiliário e o abandono pelo poder público, sendo ainda, nos últimos anos, palco do debate entre ambientalistas e urbanistas sobre o entendimento da aplicação do atual Código Florestal. Assim, este trabalho realizado nas nascentes do córrego da Aldeia, em Fernandópolis/SP, comprovou a ineficiência de todos os projetos desenvolvidos até hoje. A pavimentação asfáltica, a canalização das águas pluviais e o tamponamento de alguns trechos de cursos de água agravaram o processo erosivo. Os projetos de educação ambiental e de reflorestamento ficaram restritos a pequenas áreas, e os problemas de alagamento nunca foram enfrentados. A implantação do parque linear do córrego da Aldeia demonstra ser uma alternativa viável para o município, resgatando e mobilizando a população, transformando a convivência com os cursos d'água no meio urbano e atingindo os objetivos desejados nos níveis social, cultural e ecológico, sem comprometer o importante papel das áreas de fundo de vale na manutenção da biodiversidade e do equilíbrio ambiental.

Palavras-chave: Parques lineares. Planejamento urbano. Área de preservação permanente. Drenagem urbana. Urbanização.

\section{Abstract}

Urban policies lead to the occupation of the valley bottoms without respecting the natural dynamics, applying the environmental legislation and the urbanistic instruments in a similar way to the rural area. In addition, these areas suffer with real estate market devaluation and abandonment by the public authorities. In recent years environmentalists and urbanists have debated on the understanding of the current Forestry Code application in urban areas. Thus, this work carried out in Fernandópolis, SP, in the sources of the Aldeia stream, proved the inefficiency of all projects developed to date. Asphalt paving, rainwater piping and the buffering of some stretches of watercourses aggravated the erosive process. Environmental education and reforestation projects were restricted to small areas and flooding problems were never addressed. The implantation of the linear

RHAC é arquiteto e urbanista, mestre, e-mail: rhacorrea@gmail.com

GHV é engenheira agrônoma, doutora, e-mail: gisele.vazquez@universidadebrasil.edu.br LSV é engenheiro agrônomo, doutor, e-mail: luiz.vanzela@universidadebrasil.edu.br 
park of the Aldeia stream demonstrates to be a viable alternative, rescuing and mobilizing the local population, transforming the coexistence with the urban waterways and achieving the desired goals at social, cultural and ecological levels without compromising the important role of valley bottom areas in maintaining biodiversity and environmental balance.

Keywords: Linear parks. Urban planning. Permanent preservation areas. Urban drainage. Urbanization.

\section{Introdução}

Há muito tempo observa-se uma estreita relação entre a localização das cidades e a existência de cursos d'água. Isso se deve, principalmente, às características associadas à presença dos rios nos núcleos urbanos - além de fornecer água potável, possibilitam controle do território, subsistência, meio de circulação de pessoas e bens, energia hidráulica e opções de lazer (Costa, 2006). Para Costa (2002) apud Porath \& Afonso (2006, p. 163), o papel dos cursos d'água na estruturação urbana seria análogo ao de espinhas dorsais, "[...] tornando-se muitas vezes eixos de desenvolvimento do desenho da cidade [...]".

0 processo de urbanização brasileiro também indica a importância dos cursos d'água para a localização das cidades. A começar pelas cidades coloniais que, mesmo quando situadas em baías ou à beira-mar, guardam proximidade com as margens dos rios. "É, portanto, a partir de rios - grandes, médios ou pequenos cursos d'água - que muitos núcleos urbanos brasileiros vão surgir [...]" (Costa, 2006, p. 10).

As alterações ocorridas na forma de produção da economia e na estrutura social, a partir do início do século $\mathrm{XX}$, provocaram um intenso ciclo migratório do campo para as cidades. Como consequência ocorreu um colapso da infraestrutura urbana, bem como o fim da relação harmoniosa dos rios com as cidades. Atualmente, a discussão ambiental promovida no âmbito global trouxe novamente para o debate a importância de se tratar dos recursos hídricos de forma sustentável. Nesse contexto, o Plano Diretor do município de Fernandópolis/SP, aprovado em outubro de 2006, instituiu, por meio do capítulo II, artigo 16, inciso VIII, os parques lineares dos córregos Santa Rita, do Engenho e da Aldeia, como forma de resgatar os fundos de vale e os cursos d'água como áreas de convívio, de lazer e de contemplação inseridos na paisagem urbana. No entanto, não há nenhum projeto de implantação desses parques lineares.
Este artigo descreve as condições atuais da ocupação do fundo de vale do córrego da Aldeia, especificamente nas nascentes localizadas no perímetro urbano do município de Fernandópolis, propondo um modelo de ocupação fundamentado na implantação do parque linear, resgatando a interação e a proteção dos recursos hídricos com a ocupação urbana.

\section{O processo de urbanização no Brasil}

No Brasil, a formação dos primeiros núcleos urbanos ocorreu no período de colonização portuguesa. Por razões estratégicas de deslocamento e de defesa, esses núcleos se instalaram às margens de rios que desaguavam em todo litoral brasileiro. Durante todo o período de colonização brasileira, reproduziu-se a relação harmoniosa entre os núcleos urbanos $\mathrm{e}$ os rios que desaguavam em toda a costa brasileira. Dessa forma, quase todas as capitais estabeleceram uma dependência de seus mananciais sobre vários aspectos, como deslocamento, lazer, abastecimento, fontes de água doce, entre outros (Costa, 2006).

A alteração no processo de urbanização ocorrida ao longo dos anos transformou o perfil demográfico brasileiro, a população rural migrou para as cidades e o país se tornou majoritariamente urbano. Esse intenso processo migratório provocou uma rápida degradação do espaço urbano, causando poluição e deterioração das condições ambientais, expulsando as populações de suas áreas de fundo de vale, que antes eram palco de práticas de esporte e de lazer (Travassos, 2010). Segundo Moretti (2005), houve uma ruptura nos últimos 100 anos na relação das pessoas que vivem no meio urbano com suas áreas de fundo de vale. Essas áreas, que antes eram vistas como locais importantes para o cotidiano dos primeiros núcleos urbanos, passaram a ser causadoras de inúmeros problemas ambientais, como enchentes, e, por consequência, de saúde pública. 
No Brasil, quase $40 \%$ da população vive nas regiões metropolitanas. Esse grande contingente também concentra a riqueza e a pobreza em espaços cada vez mais densos e em constante pressão sobre os recursos naturais (Brito, 2006). Segundo Bueno (2008), nossas cidades são resultado da estrutura social, caracterizada por diferentes condições de vida e de acesso a serviços e equipamentos urbanos, onde a ausência de uma política habitacional provoca a proliferação de assentamentos irregulares, sem saneamento ambiental, ocupando as áreas de várzea e as encostas de morros que não interessam ao mercado imobiliário. Para Rolnik (1999), esse modelo de produção das cidades brasileiras é fruto de um urbanismo de risco, caracterizado pela produção espontânea de habitação de baixa qualidade, em locais sem qualquer acesso às infraestruturas urbanas, sem comprovação da titularidade da posse, o que faz com que essas populações sofram diversos riscos por viver em locais vulneráveis. No entanto, o risco não é somente das populações excluídas, porque o efeito dessa forma de ocupação do território urbano tem se mostrado insustentável, com consequências para toda a cidade. Os efeitos são sentidos todos os anos, agravando-se com o passar do tempo. São congestionamentos cada vez maiores, enchentes, deslizamentos, que colocam a cidade em colapso.

Para Tucci (2008), embora nos países desenvolvidos a fase higienista e sanitarista dos projetos de canalização e de retificação das áreas de fundo de vale tenham sido superadas por uma visão sustentável do ponto de vista ambiental, propondo o regaste ao convívio das cidades de suas áreas de mananciais, essa etapa ainda não foi superada no Brasil. 0 país continua com baixa cobertura de coleta, esgotamento e tratamento de esgotos, que continuam sendo lançados, sem qualquer tratamento, em nossos mananciais. Os projetos de retificação e de canalização das áreas de fundo de vale, com a construção de avenidas marginais, fazem parte da grande maioria de projetos urbanos sem qualquer preocupação com a importância dessas áreas para o ciclo hidrológico.

\section{A ocupação dos fundos de vale nas áreas urbanas}

Atualmente, há uma grande preocupação em tratar os sistemas fluviais em ambientes urbanos de forma integrada com a paisagem e em equilíbrio com os ecossistemas existentes. Essa nova abordagem surge da preocupação com o aquecimento global pelos organismos internacionais. A Organização das Nações Unidas (ONU) vem promovendo debates entre as nações com objetivo de alcançar o equilíbrio entre o desenvolvimento econômico e a sustentabilidade ambiental e, assim, restabelecer as condições ambientais e os ecossistemas planetários (Meneguetti, 2007).

Em 2002, foi realizada a Conferência das Nações Unidas, conhecida como Cúpula Mundial sobre Desenvolvimento Sustentável ou Rio+10, em Johanesburgo, na África do Sul, na qual se avaliaram os documentos propostos na conferência anterior, sobretudo a Agenda 21, chegando-se a conclusão de que as propostas não saíram do papel e de que quase nada havia sido implementado pelos países que participaram do encontro.

Proteger e fazer uso racional dos recursos hídricos tornou-se uma tarefa essencial para governos em todo o planeta. No Brasil, embora haja ainda muito desperdício e mau uso dos mananciais, são baixíssimos os índices de coleta e de tratamento adequado de esgotos (Tucci, 2005).

Segundo Bueno (2008), para que os rios deixem de ser canais de afastamento de esgotos, é necessário superar a visão de que o melhor lugar para a avenida é o fundo de vale e recuperar a capacidade de convívio com a rede hidrográfica. Essas faixas marginais aos cursos d'água passam a ter reconhecimento de seus valores funcionais, sanitários, sociais e ambientais de forma integrada no meio urbano.

De acordo com Moretti (2005), existe uma clara dualidade entre os projetos de intervenção nas áreas de fundo de vale, já que, por um lado, é necessário restabelecer a vegetação ciliar para propiciar a recomposição dos ambientes naturais e a recuperação da biodiversidade; por outro, em áreas urbanizadas, amplamente sujeitas às ações antrópicas, há a necessidade de flexibilização das regras legais para poder viabilizar as estratégias de reaproximação do cidadão com os cursos d'água no meio urbano. Além disso, esse planejamento territorial deve ser específico a partir de cada bacia hidrográfica.

No Brasil, esses sistemas são chamados de parques lineares. E é justamente sua capacidade de interconectar áreas importantes para os ecossistemas que potencializam os benefícios dessas áreas para os processos naturais nas cidades. 


\section{Parques lineares como instrumento de recuperação das áreas de fundo de vale}

Segundo Cardoso (2009), o fundo de vale compõe uma parte fundamental da geomorfologia e é onde ocorrem diversos processos naturais do planeta. O escoamento da água nos vales é parte importante do ciclo da água, por atuar como agente geológico nos processos erosivos, no transporte e na sedimentação, delimitando diferentes estágios fluviais.

Para Gorski (2010), a bacia hidrográfica é o conjunto de cursos d'água dentro de uma área delimitada pelos pontos mais altos de sua superfície. Em uma bacia hidrográfica, todos os cursos d'água convergem para um único ponto de vazão. 0 ecossistema fluvial está ligado estruturalmente às bacias hidrográficas e integrado aos sistemas que compõem o ciclo hidrológico.

Considerando a importância dos mananciais para o equilíbrio dos ecossistemas rurais e urbanos e a dinâmica hidrológica relacionada à geomorfologia fluvial, é consenso entre os profissionais que atuam no planejamento das cidades a necessidade de que os projetos de intervenções nas áreas de fundo de vale sejam fundamentados em uma visão integrada de toda bacia hidrográfica, atuando de forma multissetorial, com a adoção de medidas estruturais e não estruturais (Tucci, 2005).

Para Tucci (2006), o planejamento urbano no Brasil está desconectado com as ações referentes aos recursos hídricos, e sua implantação é executada de forma desorganizada em relação à infraestrutura urbana. As obras são implantadas com base apenas nos aspectos setoriais, dentro de uma visão pontual, utilizando-se de técnicas de engenharia tradicionais de drenagem urbana, incapazes de abranger a complexidade do ciclo hidrológico. Em geral, o proprietário das áreas protegidas por lei não tem interesse em garantir a manutenção delas, pois são áreas sem valor para o mercado imobiliário, que deveriam ser resgatadas pelo poder público; portanto, cumprem função socioambiental e de valor incalculável para a sustentabilidade (Tucci, 2008).

Durante a aprovação do atual Código Florestal Brasileiro (Brasil, 2012), em maio de 2012, ocorreu um intenso debate na sociedade brasileira sobre as propostas de alterações na demarcação das áreas de preservação permanente (APPs). 0 debate contrapôs a visão de ambientalistas, urbanistas, geógrafos, engenheiros ambientais, engenheiros agrônomos, juristas e demais profissionais que militam na área. No Brasil, um grande problema para a estratégia municipal de ocupação das áreas de fundo de vale é a falta de ações integradas entre o planejamento urbano e as demais políticas municipais, tais como os resíduos sólidos e a drenagem urbana, sendo cada tema gerenciado por uma secretaria sem uma coordenação integrada (Tucci, 2003).

Há várias experiências internacionais exitosas de implantação de parques lineares como instrumento de intervenção nos fundos de vale urbanos. Atualmente, a experiência de grande repercussão no Brasil e na mídia internacional é o projeto de Seul, na Coreia do Sul, de renaturalização do rio Cheonggyecheon, curso d'água que corta a capital sul-coreana, canalizado na década de 1960 para a implantação de um viaduto expresso no centro da cidade. Conforme Lucas (2008), em 2002, o projeto teve início com a demolição de $6 \mathrm{~km}$ do viaduto, o destamponamento e a restauração do rio, com investimentos pesados nos sistemas de drenagem e tratamento do esgoto.

De acordo com Gorski (2010), no Brasil, um dos primeiros projetos de recuperação de rios urbanos é o Projeto Beira-Rio, realizado pela prefeitura de Piracicaba para a requalificação ambiental e urbanística do rio Piracicaba. 0 projeto de intervenção definiu como objetivos a requalificação da qualidade da água, a preservação do cinturão meândrico, a reestruturação do tecido urbano, o incentivo do rio como caminho, a conservação da paisagem e a conexão do cidadão ao rio.

\section{Caracterização territorial}

O local escolhido para realização deste trabalho foi o município de Fernandópolis, localizado a 550 km da capital São Paulo, na região noroeste do Estado, com uma população total estimada de 68.399 habitantes (IBGE, 2016). Apresenta clima tropical semiúmido, com inverno seco e verão chuvoso, com precipitação média de $1.362 \mathrm{~mm}$. Conforme descrição do Instituto Brasileiro de Geografia e Estatística (IBGE, 1993), no município de Fernandópolis predominam os seguintes grupos de vegetação no domínio da Mata Atlântica: encraves de cerrado com estepe e zonas de tensão ecológica e floresta estacional semidecidual.

A análise das condições encontradas no local de estudo deste trabalho proporcionou a elaboração do diagnóstico abordando as características da 
geomorfologia, da vegetação, da qualidade da água, dos instrumentos urbanísticos e da regularidade fundiária. A metodologia adotada contou com a pesquisa dos documentos disponíveis na prefeitura local, principalmente do Caderno de Diagnóstico do Plano Diretor do Município de Fernandópolis (Fernandópolis, 2004), elaborado pela Prefeitura Municipal de Fernandópolis em parceria com a Universidade Federal de São Carlos (UFSCar) no ano de 2004, e do relatório de caracterização da vegetação de mata ciliar elaborado pela Secretaria Municipal do Meio Ambiente em 2010. Complementando a metodologia, foram realizadas visitas ao local de estudo, registro fotográfico e análise laboratorial para avaliar a qualidade da água. Com base no diagnóstico, foi possível elaborar a proposta final, bem como um levantamento de custos, para a criação do parque linear do córrego da Aldeia. Essa proposta prevê um cenário desejado para a implantação do parque linear, embasada nos critérios definidos pelo Plano Diretor Municipal para intervenção nas áreas de fundo de vale.

\section{Caracterização da geomorfologia}

Segundo Ross \& Moroz (1997), citados no Caderno de Diagnóstico do Plano Diretor de Fernandópolis, o relevo do município se caracteriza como uma unidade morfoestrutural da bacia sedimentar do Paraná, classificada como Planalto Ocidental Paulista, apresentando: ao norte, colinas amplas e baixas, altimetria entre 450 e 550 metros, declividades dominantes entre 10 e $20 \%$ e fragilidade potencial baixa, vales pouco entalhados, densidade de drenagem baixa e potencial erosivo baixo; ao sul, colinas amplas e baixas, altimetria entre 350 e 450 metros, declividades dominantes entre 10 e $20 \%$ e fragilidade potencial média, vales entalhados, densidade de drenagem de média a alta, áreas sujeitas à forte atividade erosiva. $\mathrm{Na}$ área onde está localizada a bacia hidrográfica do córrego da Aldeia, verifica-se o predomínio de declividades acima de $20 \%$.

Analisando a distribuição espacial que cada classe de solo ocupa no município, observa-se a predominância absoluta dos Argissolos, dos quais $21 \%$ correspondem aos solos PVA1, e 77\%, aos solos PVA10. Na área onde está localizada a bacia do córrego da Aldeia, predominam os solos do tipo Argissolos PVA 1.
A análise da carta de suscetibilidade à erosão laminar relativas às classes de suscetibilidade alta $\mathrm{e}$ muito alta ocorrem, principalmente, nas nascentes dos principais mananciais, localizados na área urbana de Fernandópolis. 0 córrego da Aldeia está localizado em uma região de alta suscetibilidade à erosão laminar.

Os processos erosivos nas margens do córrego da Aldeia se encontram em estágio avançado, decorrentes da supressão da mata ciliar e agravados pela impermeabilização do solo que aumenta a velocidade de escoamento superficial. 0 lançamento da rede de canalização das águas pluviais diretamente nos cursos d'água, sem nenhuma preocupação com sistemas de dissipação de energia, também colabora para o agravamento dos processos erosivos, causando assoreamento do córrego, conforme demonstram as Figuras 1 e 2.

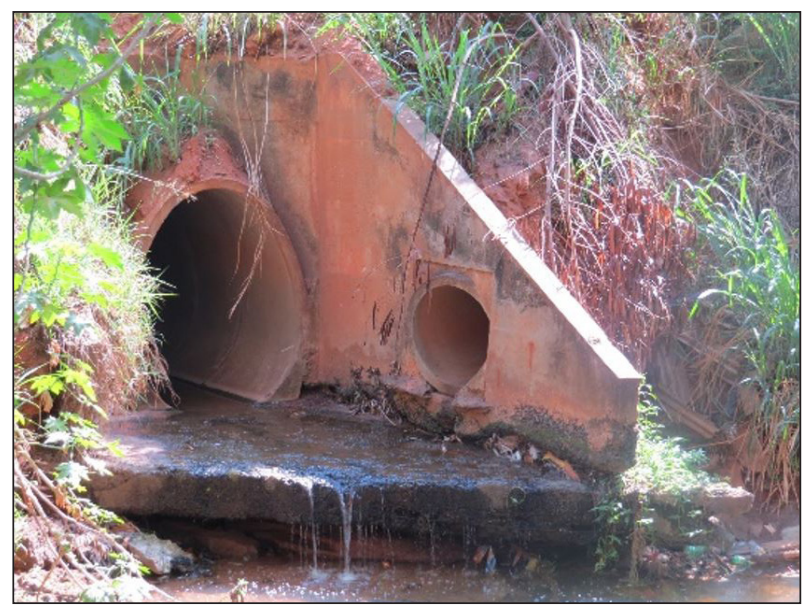

Figura 1- Rede de drenagem e processos erosivos Fonte: Os autores (2014).

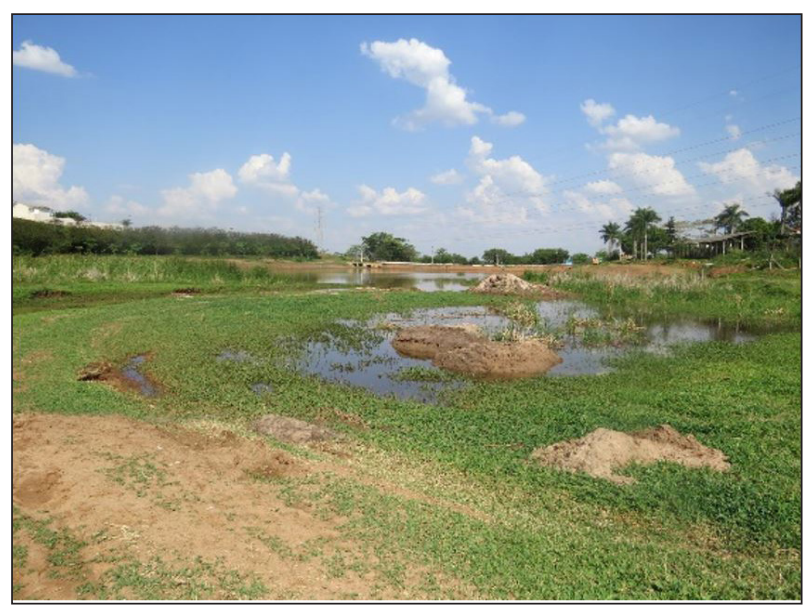

Figura 2 - Rede de drenagem e processos erosivos Fonte: Os autores (2014). 


\section{Vegetação de mata ciliar}

De acordo com o relatório elaborado pela Secretaria Municipal do Meio Ambiente em 2010 (Fernandópolis, 2010) referente à mata ciliar, existem, no local, espécies vegetais em duas situações: árvores isoladas e maciços degradados com espécies nativas e exóticas. Nos 20,50 hectares de APPs, foram encontradas 71 árvores isoladas, das quais $62 \%$ constituem espécies nativas, tais como: Almecegueira (Protium heptaphyllum (Aubl.) Marchand), Amendoim (Pterogyne nitens), Canela-fedida (Nectandra cissiflora sp), Canelinha (Ocotea sp), Cedro (Cedrela Fissilis Vell.), Embaúba (Cecropia pachystachya Trecul.), Farinha-Seca (Albizia niopoides Benth.), Goiabeira (Psidium sp), Ipê-Amarelo (Handroanthus chrysotricha), Jacarandá (Machaerium aculeatum Raddi), Jenipapo (Genipa americana L.), Jerivá (Syagrus romanzoffiana (Cham.) Glassman), Leucena (Leucaena leucocephala), Macaúva (Acrocomia aculeata (jacq) Lodd. ex Mart.), Mamica-de-Porca (Zanthoxylum rhoifolium Lam.), Pêssego-do-Mato (Hexachlamys edulis (0. Berg.)) e Urucum (Bixa Orellana L.). Os outros $38 \%$ são de espécies exóticas, tais como: Abacateiro (Persea americana Mill.), Calabura (Muntingia calabura L.), Espatódia (Spathodea campanulata), Jambolão (Syzygium cumini) e Limoeiro (Citrus limonum). Entre os maciços florestais degradados, que somam 1,60 hectare, ou seja, 7,8\% da área total de APPs, aproximadamente $43 \%$ são constituídos, predominantemente, de espécies nativas, e $57 \%$, de espécies exóticas.

As áreas de várzeas apresentam a ocorrência de Taboa (Typha domingensis) e Aguapé (Eichhornia crassipes). Além disso, nas áreas úmidas, é possível verificar a ocorrência de diversas plantas características de área alagada, conforme pode ser observado nas Figuras 3 e 4.

\section{Qualidade da água}

A bacia do córrego da Aldeia, na região objeto de estudo deste trabalho, ocupa uma área de $5,14 \mathrm{~km}^{2}$, possuindo três nascentes com características muito diversas quanto ao estágio de ocupação e uso do solo. Essas três nascentes se juntam para formar o córrego da Aldeia, que, mais a jusante, abastece o lago da represa Beira Rio, as margens da Avenida Augusto Cavalin, cruzando os bairros Jardim Araguaia, Jardim

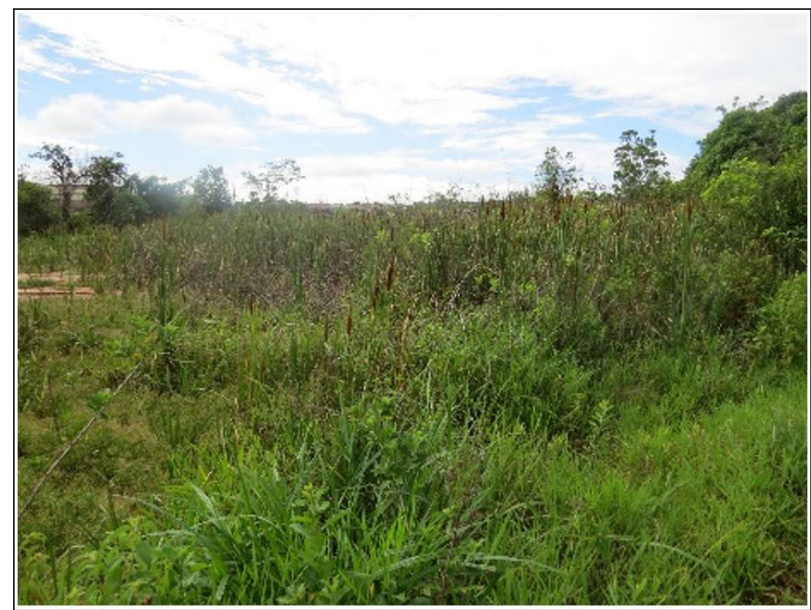

Figura 3 - Vegetação de mata ciliar

Fonte: Os autores (2014).

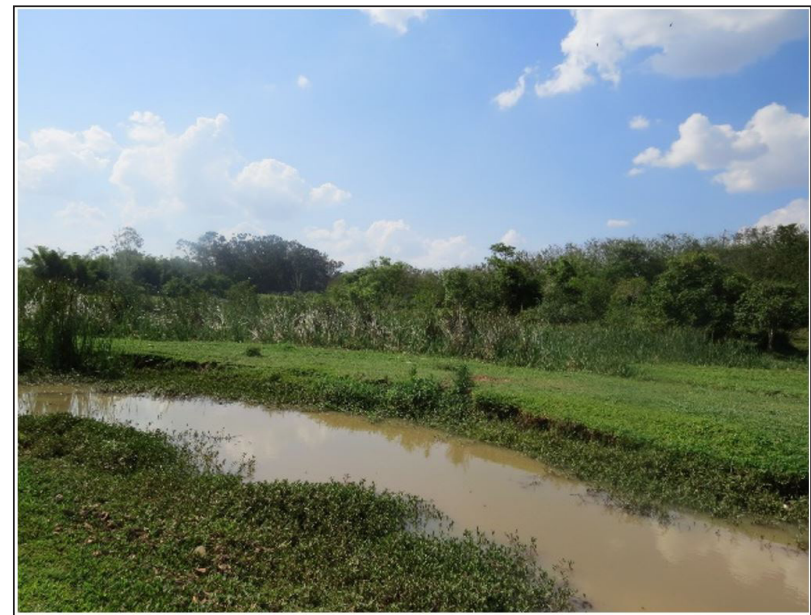

Figura 4 - Vegetação de mata ciliar Fonte: Os autores (2014).

Alto das Paineiras, Jardim Terra das Paineiras, Jardim Botelho, Jardim Terra Verdi e a fazenda de propriedade do sr. Manoel Terra Verdi.

A classificação dos corpos d'água, utilizada para estabelecer o tipo de uso de um manancial, foi regulamentada pela Resolução no 357 do CONAMA (Brasil, 2005), que utiliza como parâmetro a qualidade da água. Segundo Bocchiglieri (2010), o córrego da Aldeia está enquadrado na classe 4; dessa forma, os usos permitidos são a navegação e a harmonia paisagística, porém as coletas de suas amostras foram realizadas em um ponto localizado após receber o lançamento das águas da nascente localizada no fundo de vale da Avenida Getúlio Vargas. Para Moretti (2005), a qualidade da água está diretamente 
ligada às ligações clandestinas de esgoto na rede de drenagem pluvial. Outra fonte poluidora que prejudica a qualidade das águas urbanas são as águas pluviais de escoamento superficial. É grande a carga poluente que é transportada para os mananciais pela drenagem urbana, principalmente no início do período de chuvas.

Para determinar a qualidade da água, na área objeto deste estudo, e relacioná-la com a intensidade da ação antrópica, foram realizadas análises laboratoriais de ensaios físico-químicos e ensaios microbiológicos. Para a coleta das amostras, o critério adotado foi realizar a coleta em três pontos distintos, com características diferentes quanto à intensidade da intervenção antrópica. 0 primeiro ponto de coleta escolhido foi próximo à nascente existente no Jardim Araguaia, no início da Avenida dos Tangarás. 0 segundo ponto de coleta foi realizado a aproximadamente 1.000 metros a jusante da nascente. 0 terceiro ponto de coleta foi realizado próximo à nascente, que está localizada dentro da fazenda de propriedade do sr. Manoel Terra Verdi, conforme Figura 5.

As coletas das amostras foram realizadas aproximadamente uma hora após as chuvas que ocorreram nos dias 2 de outubro de 2014 e no dia 3 de novembro de 2014. 0 resultado das análises laboratoriais demonstra que, no local de estudo deste trabalho, considerando a Resolução n 357 do CONAMA (Brasil, 2005), o córrego da Aldeia pode ser classificado como classe 2 , sendo permitidas a pesca amadora e a recreação de contato secundário, viabilizando, dessa forma, a criação do parque linear, sem a necessidade de grandes obras de saneamento. Os resultados estão apresentados na Tabela 1.

\section{Instrumentos urbanísticos}

O mapa de evolução urbana, que faz parte do Caderno de Diagnóstico do Plano Diretor de Desenvolvimento Urbano (Fernandópolis, 2004), demonstra que os primeiros bairros implantados no local de estudo deste trabalho foram o Jardim Araguaia em 1979 e o Alto das Paineiras no início dos anos de 1990. Pela Lei Federal no 6.766 (Brasil, 1979), aprovada em dezembro de 1979, os municípios foram obrigados a elaborar suas leis de parcelamento de solo, condicionando a aprovação do loteamento à implantação da infraestrutura. Esse processo foi sendo gradativamente incorporado às leis municipais de parcelamento do solo. A ausência de regras sobre o parcelamento de solo nesse período é a principal causa da falta da infraestrutura nas periferias

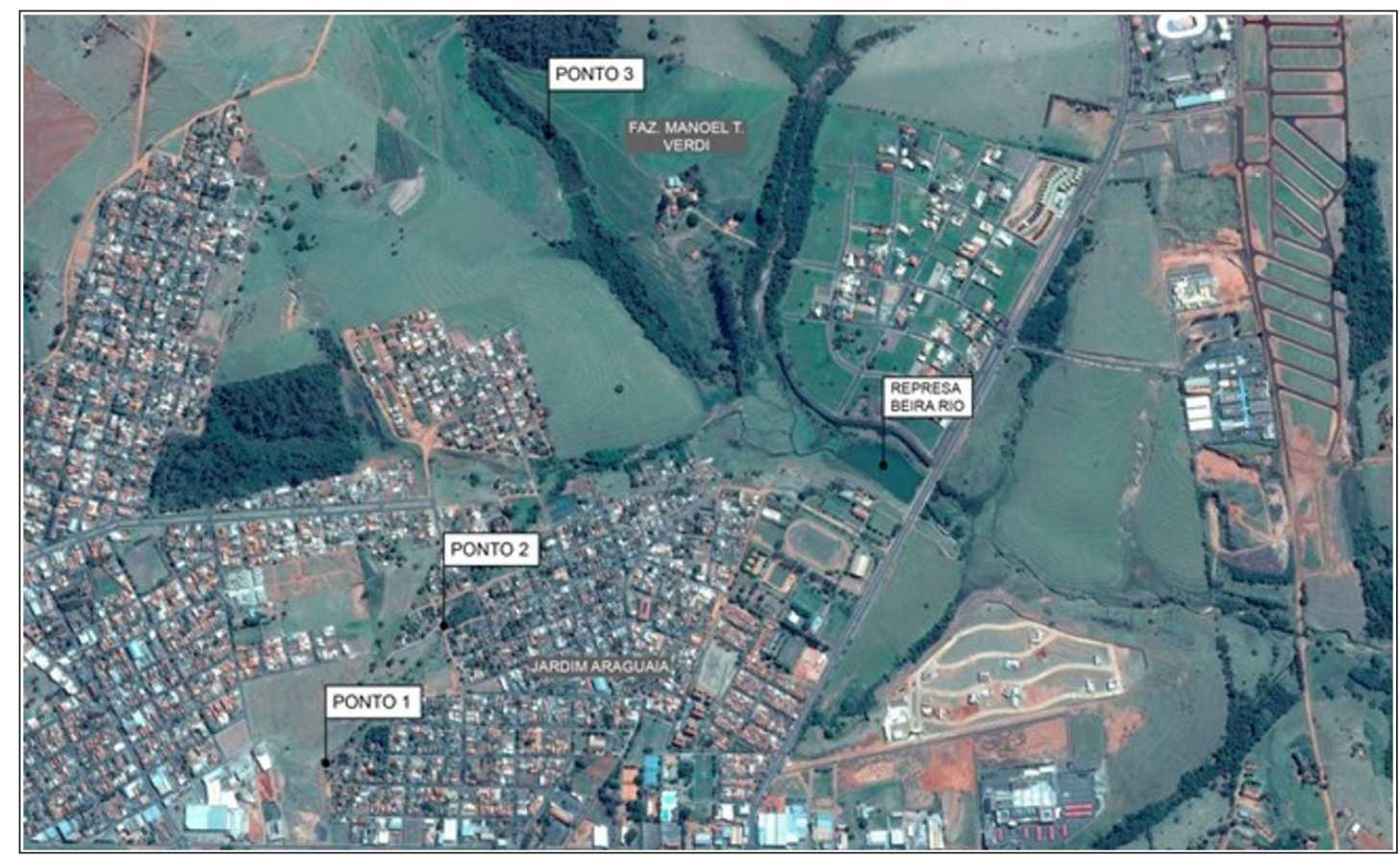

Figura 5 - Mapa de localização dos pontos de coleta Fonte: Google Inc. (2014) adaptado. 
Tabela 1 - Análise dos parâmetros físico-químicos e biológicos de qualidade de água. Fernandópolis-SP (2014)

\begin{tabular}{|c|c|c|c|c|}
\hline \multicolumn{5}{|c|}{ Resultados dos ensaios laboratoriais - Físico-químicos } \\
\hline & Unidade & $\begin{array}{l}\text { Ponto de coleta } 1 \\
\text { Nascente }\end{array}$ & $\begin{array}{l}\text { Ponto de coleta } 2 \\
1.000 \mathrm{~m} \text { a jusante }\end{array}$ & $\begin{array}{l}\text { Ponto de coleta } 3 \\
\text { Faz. Manoel Verdi }\end{array}$ \\
\hline Sólidos suspensos voláteis & $\mathrm{mg} / \mathrm{L}$ & 32 & $<5$ & 6 \\
\hline Mercúrio total & $\mathrm{mg} / \mathrm{L}$ & $<0,0005$ & $<0,0005$ & $<0,0005$ \\
\hline Cromo total & $\mathrm{mg} / \mathrm{L}$ & $<0,02$ & $<0,02$ & $<0,02$ \\
\hline Arsênio total & $\mathrm{mg} / \mathrm{L}$ & $<0,007$ & $<0,007$ & $<0,007$ \\
\hline Níquel total & $\mathrm{mg} / \mathrm{L}$ & $<0,02$ & $<0,02$ & $<0,02$ \\
\hline Selênio total & $\mathrm{mg} / \mathrm{L}$ & 0,01 & $<0,005$ & $<0,005$ \\
\hline Antimônio & $\mathrm{mg} / \mathrm{L}$ & $<0,004$ & $<0,004$ & $<0,004$ \\
\hline Condutividade elétrica & $\mu \mathrm{S} / \mathrm{cm}$ & 368,4 & - & 79,13 \\
\hline Turbidez & NTU & $<0,07$ & $\cdot$ & 3,46 \\
\hline Demanda bioquímica de oxigênio & $\mathrm{mg} / \mathrm{L}$ & 2,7 & 2,6 & 2,6 \\
\hline Estanho & $\mathrm{mg} / \mathrm{L}$ & $<0,1$ & $<0,1$ & $<0,1$ \\
\hline Demanda bioquímica de oxigênio solúvel & $\mathrm{mg} / \mathrm{L}$ & 2,5 & 2,5 & 2,5 \\
\hline Chumbo total & $\mathrm{mg} / \mathrm{L}$ & $<0,008$ & $<0,008$ & $<0,008$ \\
\hline Zinco total & $\mathrm{mg} / \mathrm{L}$ & 0,08 & 0,1 & 0,04 \\
\hline Cádmio total & $\mathrm{mg} / \mathrm{L}$ & $<0,004$ & $<0,004$ & $<0,004$ \\
\hline Cobre & $\mathrm{mg} / \mathrm{L}$ & 0,03 & $<0,02$ & $<0,02$ \\
\hline Sólidos suspensos totais & $\mathrm{mg} / \mathrm{L}$ & 36 & 16 & 12 \\
\hline \multicolumn{5}{|c|}{ Resultados dos ensaios laboratoriais - Microbiológicos } \\
\hline Coliformes totais & UFC/100mL & $<1,0 \times 10^{0}$ & $<1,0 \times 10^{0}$ & $<1,0 \times 10^{0}$ \\
\hline Escherichia coli & UFC/100mL & $<1,0 \times 10^{\circ}$ & $<1,0 \times 10^{\circ}$ & $<1,0 \times 10^{\circ}$ \\
\hline
\end{tabular}

Fonte: Dados dos autores (2014).

urbanas, tornando-se um problema urbano que ainda não foi resolvido.

0 zoneamento na área objeto de estudo deste trabalho foi estabelecido pela Lei Municipal no 1.082 (Fernandópolis, 1986), aprovada em outubro de 1986. Posteriormente, os parâmetros urbanísticos foram incorporados ao macrozoneamento incluído no Plano Diretor, aprovado em outubro de 2006. Esses parâmetros urbanísticos estabeleceram para a área da bacia do córrego da Aldeia uma ocupação restrita, de baixa densidade populacional, com lotes grandes e alta permeabilidade do solo. No entanto, recentemente a Câmara Municipal aprovou a Lei no 4.004 (Fernandópolis, 2012), em agosto de 2012, alterando a Lei Municipal no 1.082 (Fernandópolis, 1986), o que fez com que as áreas previstas como Z2 (Zona de uso residencial 2) passassem para Z1 (Zona de uso residencial 1). Na prática, a alteração diminuiu a área dos lotes que era de $360,00 \mathrm{~m}^{2}$ para $250,00 \mathrm{~m}^{2}$, aumentando a densidade populacional, diminuindo as áreas permeáveis, contrariando todos os estudos técnicos, discutidos e elaborados de forma participativa com toda comunidade.

\section{Regularidade fundiária}

A análise da situação fundiária demonstrou uma contradição em relação à realidade encontrada no local de estudo. Quando se considera a legislação ambiental e urbanística, que determina para fins da regularização ambiental a faixa de preservação ao longo dos rios, a primeira impressão é de que o local apresenta elevado processo de invasão, pois há um grande número de edificações a poucos metros do córrego em áreas alagáveis. No período de implantação do Jardim Araguaia 
e do Residencial Alto das Paineiras, a legislação vigente que estabelecia a proteção da vegetação às margens dos cursos d'água era a do Código Florestal de 1965, instituído pela Lei Federal no 4.771 (Brasil, 1965), e a extensão da área de preservação as margens dos cursos d'água era de apenas 5 metros para córregos de até 10 metros de largura. Com a aprovação da Lei Federal no 7.803 em 1989, que alterou o Código Florestal de 1965, a faixa de proteção de 5 metros passou para 30 metros para córregos e rios de até 10 metros de largura (Brasil, 1989). E o atual Código Florestal (Brasil, 2012) também determina, para fins da regularização ambiental, a largura mínima de 30 metros de cada lado na regularização fundiária dos assentamentos inseridos em área urbana e que ocupam APPs.

Assim, após a análise dos mapas de implantação desses loteamentos com o cadastro de imóveis da Prefeitura de Fernandópolis, foi constatado que não há nenhuma invasão no local de estudo e que todas as áreas são propriedades particulares, conforme consta na aprovação do loteamento desde a sua implantação, o que pode ser comprovado pela Figura 6.

\section{O parque linear do córrego da Aldeia}

A síntese do diagnóstico das informações coletadas evidenciou o avançado estágio de degradação ambiental da bacia do córrego da Aldeia. 0 fundo de vale foi totalmente abandonado, provocando uma ruptura na relação da população com as nascentes e os cursos d'água que formam o córrego da Aldeia. Diante dessas condições, o córrego tornou-se um depósito de lixo e de restos de construção e de demolição, agravando as condições de saúde da população que vive em suas margens. Durante as visitas in loco, foi constatado o descaso total com as nascentes que dão origem ao córrego da Aldeia, nas quais não há nenhuma preocupação de proteção. As obras de drenagem urbana executadas pelo poder público despejam suas águas a poucos metros da nascente, sem cuidado com a erosão.

A supressão da mata ciliar ocorrida ao longo dos anos, aliada às condições de declividade, ao tipo de solo e ao lançamento das redes de drenagem das águas pluviais diretamente no canal, sem os elementos dissipadores de energia, provocou intenso processo erosivo, causando o assoreamento, o que diminuiu significativamente o lago da represa Beira Rio.

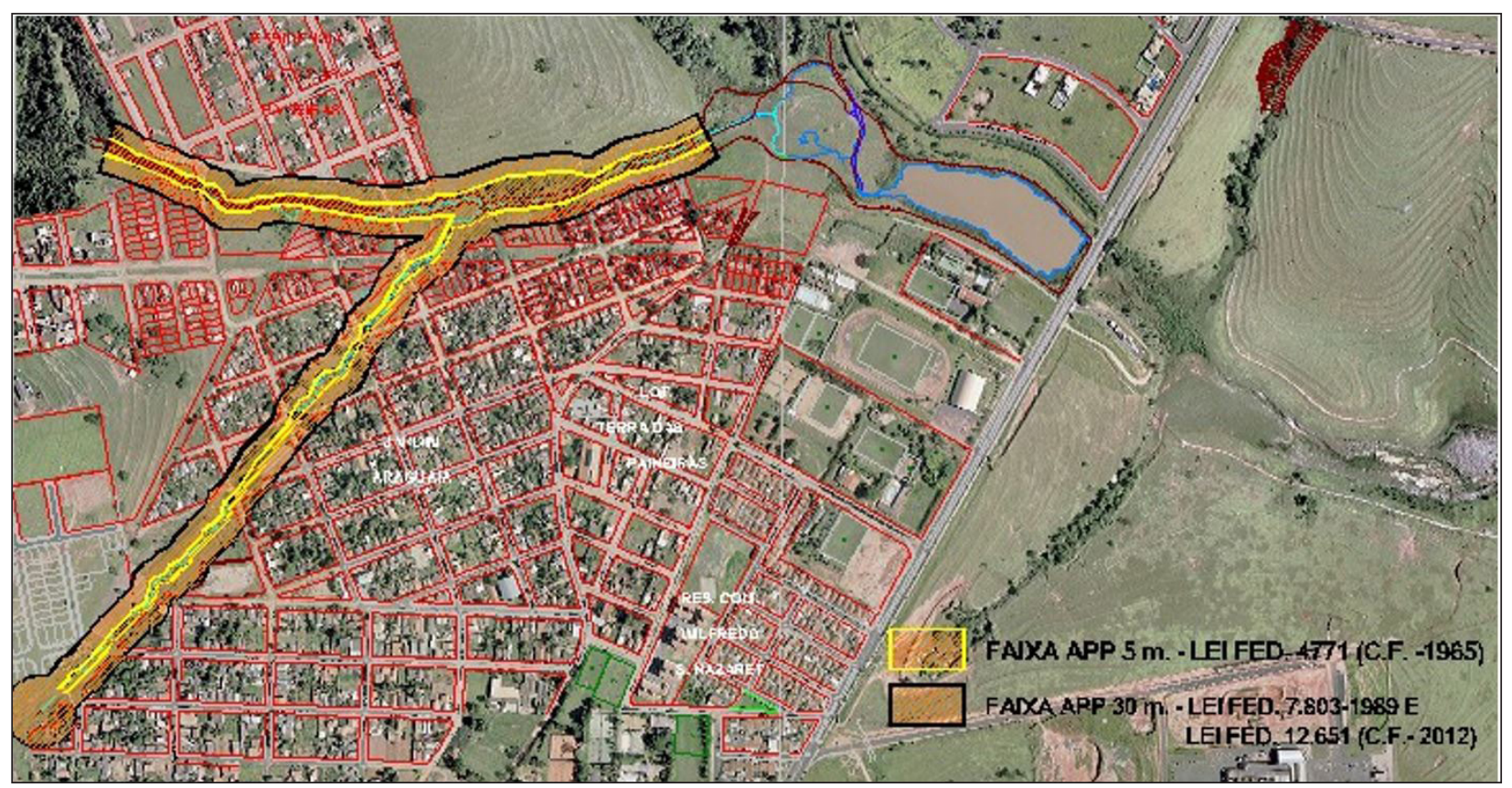

Figura 6 - Extensão da área de abrangência da faixa de APPS

Fonte: Google Inc. (2014) adaptado.

urbe. Revista Brasileira de Gestão Urbana (Brazilian Journal of Urban Management), 2018 maio/ago., 10(2), $458-472$ 
Com relação à qualidade das águas, as análises laboratoriais das amostras colhidas nos três pontos da bacia do córrego da Aldeia não apresentaram aspectos relevantes que possibilitem uma conclusão sobre a interferência da atividade antrópica na qualidade da água. 0 confronto entre os resultados não demonstrou diferenças entre os três pontos de coleta relativos à poluição por metais pesados e por agentes microbiológicos. Dessa forma, pode-se inferir que não há lançamento clandestino significativo de esgoto na rede de drenagem pluvial. Já com relação à poluição difusa, a ausência de pavimentação asfáltica, principalmente nas áreas próximas ao fundo de vale, provocando o acúmulo de partículas de solo, pode ter agido como um filtro, contribuindo para os resultados apresentados nas amostras.

As propostas elaboradas para intervenção na área objeto deste estudo consideram as diferentes paisagens e os diferentes estágios de ação antrópica diagnosticados no local, intervindo de maneira distinta em cada caso e abordando soluções para as áreas consolidadas, que produzam efeito mitigador dos problemas mencionados. Para as áreas que ainda não foram urbanizadas, as propostas deverão considerar a bacia hidrográfica como área de abrangência do planejamento urbano, incorporando na legislação urbana a implantação dos parques lineares e a infraestrutura de drenagem urbana sustentável.

Para as áreas consolidadas, necessita-se de obras de implantação de drenagem urbana sustentável, de proteção das nascentes, de reflorestamento com espécies nativas em sintonia com um trabalho contínuo de educação ambiental. Para as áreas não loteadas, além da incorporação das intervenções propostas nas áreas consolidadas, devem ser incluídos, na legislação urbanística, instrumentos que permitam o aumento da permeabilidade do solo, principalmente nas áreas de maior fragilidade ambiental definidas nos estudos do Plano Diretor de Desenvolvimento Urbano.

Para os novos loteamentos, deverá ser incorporada nas diretrizes urbanas, além da faixa de 30 metros prevista pelo Código Florestal, uma faixa de 15 metros para a implantação dos parques lineares nos fundos de vale. Na extensão do parque linear, serão implantados equipamentos de esporte e de lazer, de baixo impacto ambiental, mantendo a permeabilidade do solo e áreas para a construção de bacias de infiltração das águas pluviais, conforme Figura 7.

A Avenida dos Tangarás, prevista no projeto do loteamento do Jardim Araguaia, será implantada

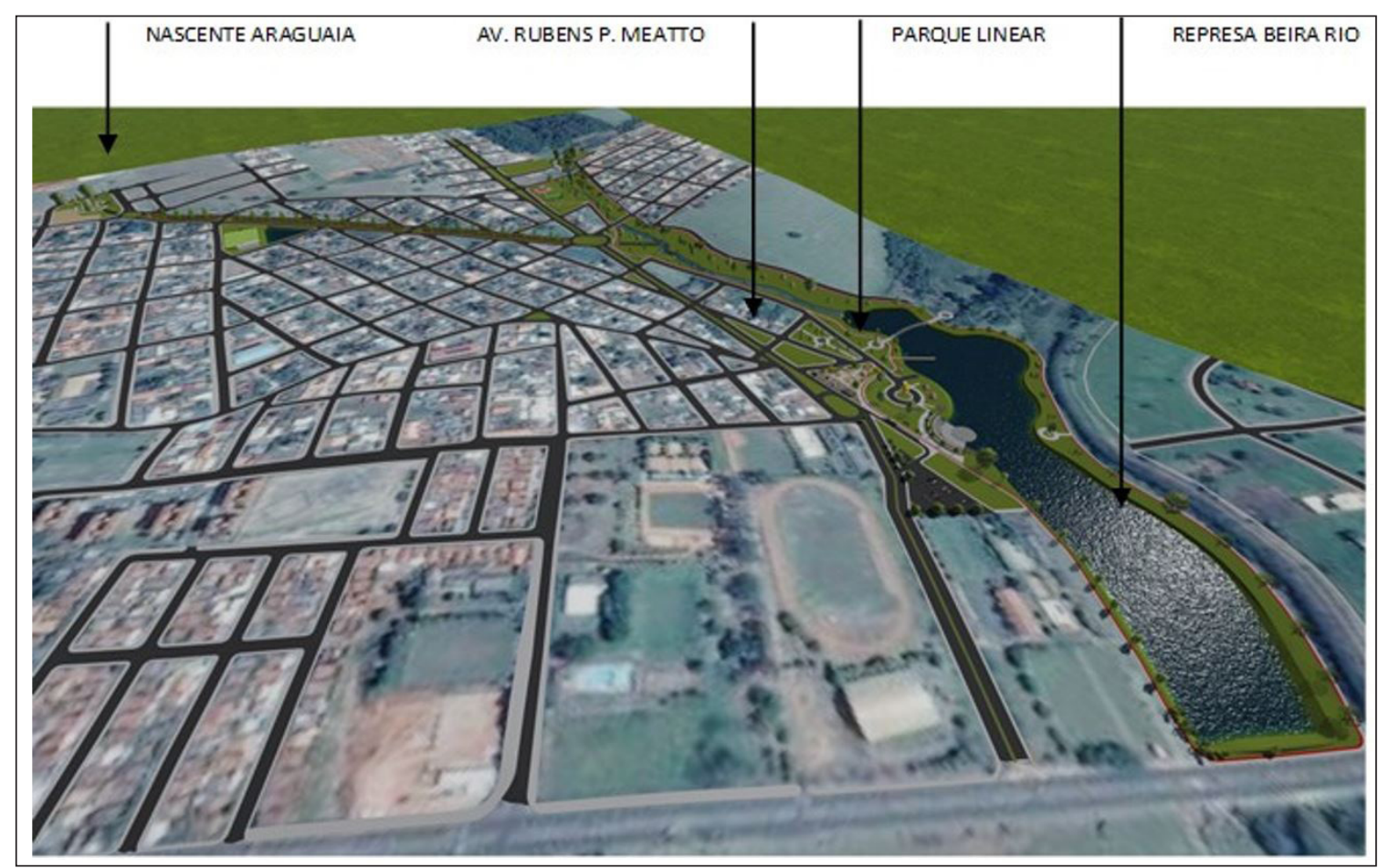

Figura 7 - Estudo de implantação de parque linear (vista da Avenida dos Tangarás)

Fonte: Os autores (2014). 
sem a canalização do córrego que deverá preservar o máximo possível o seu leito natural, promovendo apenas a estabilização das encostas com a utilização de gabiões. A faixa de rolamento da Avenida dos Tangarás será reduzida de 8 metros para 6 metros, alterando sua característica de avenida estrutural do sistema viário para avenida de trânsito local, possibilitando o alargamento dos passeios para implantação de ciclovia e de uma caixa de permeabilidade com cobertura de grama e tratamento paisagístico, conforme Figura 8.

Em todas as nascentes, deverá ser preservado o raio de 50 metros previstos pelo Código Florestal; no entanto, na nascente localizada no Jardim Araguaia, a proteção deverá ocorrer sem desapropriações, podendo, nesse caso, não permitir a abrangência do raio em todas as suas margens, conforme Figura 9.

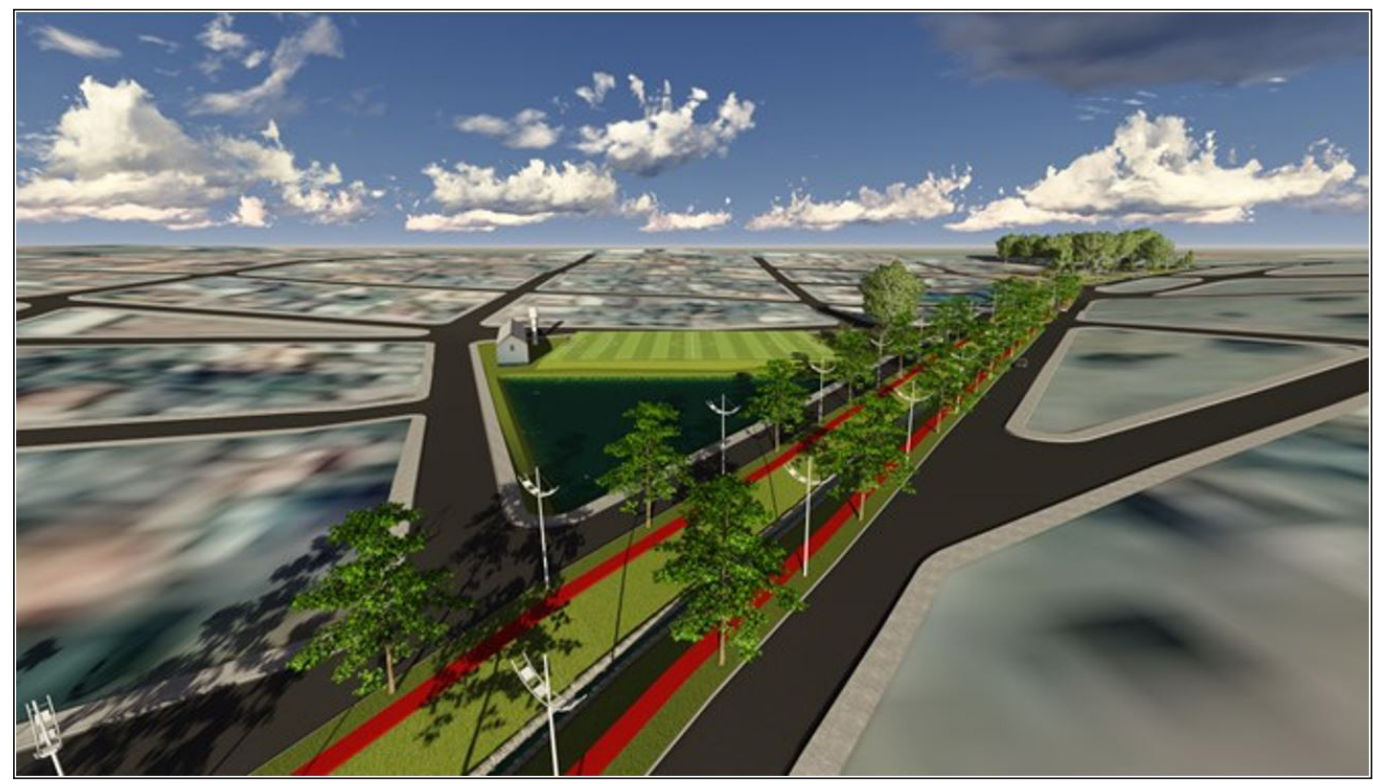

Figura 8 - Estudo de implantação de parque linear (vista da Avenida dos Tangarás) Fonte: Os autores (2014).

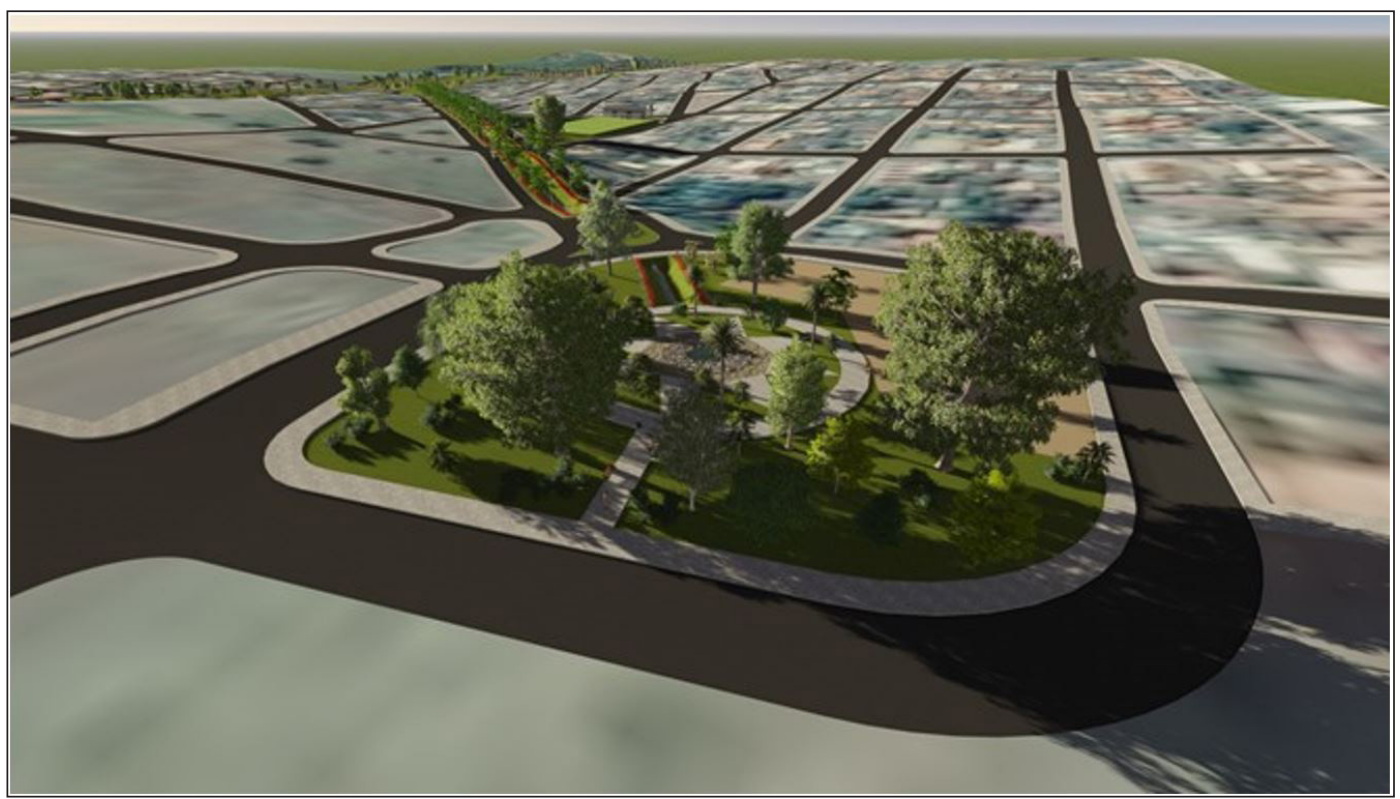

Figura 9 - Estudo de implantação de parque linear (vista da nascente no Jardim Araguaia) Fonte: Os autores (2014). 
Na nascente localizada dentro da área do antigo zoológico, o projeto prevê a criação de um espelho d'água e o reflorestamento aliado a um projeto paisagístico que permita a contemplação e a interação da população com o córrego.

0 projeto prevê ainda a recuperação total da represa Beira Rio, revitalizando toda a área no seu entorno, com espaços de lazer, esportes e cultura para a população. Para a execução das obras de recuperação, será necessário o esgotamento do lago atual a fim de desassorear e estabilizar as encostas com gabiões e reconstruir o barramento e o sistema extravasor que permita o efetivo controle das enchentes. Na margem esquerda da represa, o parque linear será implantado na extensão de 15 metros incorporados na legislação de parcelamento do solo. Na margem direita, embora sejam áreas consolidadas, há várias glebas de propriedade do município que viabilizarão a implantação dos equipamentos públicos sem a necessidade de desapropriações. 0 projeto também prevê a instalação de pistas de skate, praças com playground, concha acústica para atividades culturais, píer para esportes aquáticos e uma ponte para travessia de pedestres, conforme ilustra a Figura 10.

Com relação ao sistema viário, o projeto prevê a interligação da Avenida Rubens Padilha Meatto com a Avenida Augusto Cavalin, interligando a rodovia Percy Waldir Semeghini com a rodovia Antônio Faria, viabilizando uma rota alternativa para a Fundação Educacional de Fernandópolis e o parque de exposição agropecuária.

\section{Viabilidades ambiental, social, cultural, econômica e levantamento de custos do parque linear do córrego da Aldeia}

Quanto aos aspectos ambientais, os dados já apresentados atestam a viabilidade e a necessidade da implantação do parque linear do córrego da Aldeia em Fernandópolis, de modo a envolver o uso e a preservação de áreas verdes, contribuindo para a melhoria do transporte e da circulação dos munícipes, do manejo dos resíduos e da drenagem dos resíduos, além de proteger a vegetação ciliar, a biodiversidade local e os recursos hídricos, garantindo uma maior permeabilidade do solo, de modo a permitir uma infiltração mais lenta das águas de chuva e a criação de bacias de acumulação, reduzindo problemas de enchentes.

Já quanto aos aspectos sociais e culturais, os principais fatores positivos da implantação do

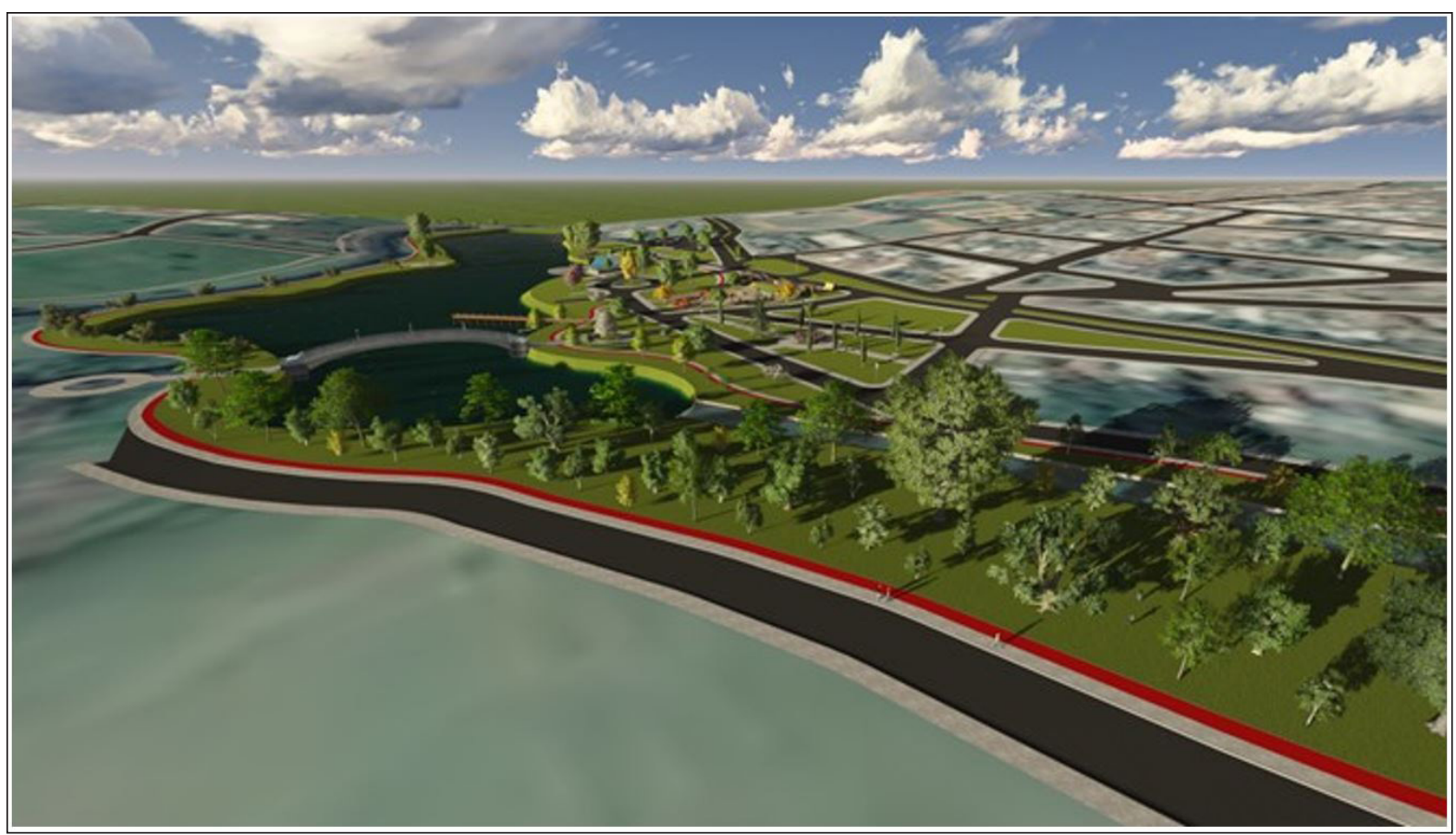

Figura 10 - Estudo de implantação de parque linear (vista do lago Represa Beira Rio) Fonte: Os autores (2014). 
parque são: a criação de um local de lazer, de modo a favorecer a educação ambiental e a coesão social, proporcionando um local para atividades com baixo custo para a população; e o incentivo a modos de transporte não motorizados e/ou de uso coletivo.

Em termos econômicos, a captação de recursos para a implantação do parque poderia ser articulada pelo poder público municipal em parceria com a iniciativa privada, em decorrência da valorização imobiliária após a realização das obras. Ressalta-se a facilidade de implantação do projeto, visto não haver a necessidade de grandes obras de saneamento, já que inexistem problemas de qualidade da água ou mesmo de invasões, pois todas as áreas do local de estudo são de propriedade particular ou do município.

Finalmente, foi realizado um levantamento detalhado do custo de implantação do parque do córrego da Aldeia em outubro de 2010, sendo seus valores corrigidos pelo IGPM para julho de 2017, ficando estimado em $\mathrm{R} \$ 33.376 .670,47$ (Tabela 2).

\section{Considerações finais}

O diagnóstico da bacia do córrego da Aldeia comprovou a ineficiência de todos os projetos desenvolvidos até hoje. A pavimentação asfáltica aumentou a velocidade de escoamento das águas pluviais e, com a canalização e o tamponamento de alguns trechos e com o lançamento direto nos cursos d'água sem os dissipadores de energia, o processo erosivo foi agravado. Os projetos de educação ambiental e de reflorestamento ficaram restritos a pequenas áreas; não houve mobilização da população local; e a manutenção das áreas foi interrompida com a descontinuidade dos programas. Os problemas de alagamento das áreas mais baixas nunca foram enfrentados. Além disso, a represa frequentemente transborda, provocando erosão e interrupção do tráfego na Avenida Augusto Cavalin.

A estratégia proposta neste trabalho para a recuperação e implantação do parque linear do córrego da Aldeia demonstra ser uma alternativa viável para o poder público, com base em um cenário possível de ser implantado e mantido pelo município, resgatando e mobilizando a população local, transformando a convivência com os cursos d'água no meio urbano e atingindo os objetivos desejados nos níveis social, cultural e ecológico, sem comprometer o importante papel das áreas de fundo de vale na manutenção da biodiversidade e do equilíbrio ambiental.

Tabela 2 - Custo estimado da implantação do parque linear do córrego da Aldeia, Fernandópolis/SP (2017)

\begin{tabular}{|c|c|c|}
\hline Discriminação & Atividades & $\begin{array}{l}\text { Custo } \\
\text { (RS) }\end{array}$ \\
\hline Projeto de sistema de captação & $\begin{array}{l}\text { Instalaç̃ões iniciais da obra } \\
\text { Serviços preliminares } \\
\text { Serviços de movimento de terra } \\
\text { Enrocamento } \\
\text { Serviços de caixa/concreto/gabiões } \\
\text { Obras de implantação de tubos } \\
\text { Serviços gerais }\end{array}$ & $24.229 .999,39$ \\
\hline Galerias de águas pluviais & $\begin{array}{l}\text { Serviç,os preliminares } \\
\text { Obras de alvenaria e concreto } \\
\text { Obras de implantação dos tubos } \\
\text { Serviços gerais }\end{array}$ & $2.821 .445,91$ \\
\hline Pavimentação asfáltica e paisagismo & $\begin{array}{c}\text { Guias e sarjetas } \\
\text { Pavimentação asfáltica e calçamento público } \\
\text { Paisagismo } \\
\text { Serviços complementares }\end{array}$ & $6.325 .225,17$ \\
\hline TOTAL & & $33.376 .670,47$ \\
\hline
\end{tabular}

Fonte: SINAPI (2010) e CPOS (2010). 


\section{Referências}

Bocchiglieri, M. M. (2010). O lixiviado dos aterros sanitários em estações de tratamento dos sistemas públicos de esgotos (Tese de doutorado). Faculdade de Saúde Pública, Universidade de São Paulo, São Paulo.

Brasil. (1965, 16 de setembro). Lei no 4.771, de 15 de setembro de 1965. Institui o Novo Código Florestal Brasileiro. Brasília: Câmara dos Deputados.

Brasil. (1979, 20 de dezembro). Lei Federal no 6766, de 19 de dezembro de 1979. Dispõe sobre o parcelamento do solo urbano e dá outras providências. Brasília: Câmara dos Deputados.

Brasil. (1989, 20 de julho). Lei Federal no 7803 de 18 de julho de 1989. Altera a redação da Lei $n^{\circ}$ 4.771, de 15 de setembro de 1965, e revoga as Leis $n{ }^{\circ}$ S 6.535, de 15 de junho de 1978, e 7.511, de 7 de julho de 1986. Brasília: Câmara dos Deputados.

Brasil. (2005, 18 de março). Resolução CONAMA nº 357 de 17 de março de 2005. Dispõe sobre a classificação dos corpos de água e diretrizes ambientais para o seu enquadramento, bem como estabelece as condições e padrões de lançamento de efluentes, e dá outras providências. Brasília: Ministério do Meio Ambiente.

Brasil. (2012, 28 de maio). Lei no 12.651, de 25 de maio de 2012. Dispõe sobre a proteção da vegetação nativa; altera as Leis nos 6.938, de 31 de agosto de 1981, 9.393, de 19 de dezembro de 1996, e 11.428, de 22 de dezembro de 2006; revoga as Leis nos 4.771, de 15 de setembro de 1965, e 7.754, de 14 de abril de 1989, e a Medida Provisória no 2.166-67, de 24 de agosto de 2001; e dá outras providências. Brasília: Câmara dos Deputados.

Brito, F. (2006). O deslocamento da população brasileira para as metrópoles. Estudos Avançados, 20(57), 221-236.

Bueno, L. M. M. (2008). Reflexões sobre o futuro da sustentabilidade urbana com base em um enfoque socioambiental. Cadernos Metrópole, 19, 99-121. http:// dx.doi.org/10.1590/8712.

Cardoso, F. J. (2009). Análise, concepção e intervenções nos fundos de vale da cidade de Alfenas - MG. Labor \& Engenho, 3(1), 1-20. http://dx.doi.org/10.20396/lobore. v3i1.1736.

Companhia Paulista de Obras e Serviços - CPOS (2010). Boletim Referencial de Custos. Versão 154. Recuperado em
30 de outubro de 2010, de http://www.cpos.sp.gov.br/ Paginas/Home.aspx

Costa, L. M. S. A. (Org.). (2006). Rios e paisagens urbanas. Rio de Janeiro: Viana \& Mosley Editora/Editora PROURB.

Fernandópolis. (1986, 6 de janeiro). Lei no 1082 de 06 de janeiro de 1986. Estabelece normas de ocupação do Território do Município de Fernandópolis e dá outras providências. Fernandópolis: Poder legislativo.

Fernandópolis. (2004). Caderno de Diagnóstico do Plano Diretor de Desenvolvimento Urbano de Fernandópolis $[112$ p.). Fernandópolis: Diretoria de Planejamento.

Fernandópolis. (2010). Caracterização da vegetação nas nascentes do córrego da Aldeia (9 p.). Fernandópolis: Secretaria Municipal de Meio Ambiente.

Fernandópolis. (2012). Lei no 4004 de 23 de agosto de 2012. Altera dispositivos da lei 1082 de 06 de janeiro de 1986, que dispõe sobre as normas de ocupação do território do município de Fernandópolis e dá outras providências. Fernandópolis: Poder legislativo.

Google Inc. (2014). Google Earth. Mountain View: Google Inc.

Gorski, M. C. B. (2010). Rios e cidades: ruptura e reconciliação. São Paulo: SENAC.

Instituto Brasileiro de Geografia e Estatística - IBGE. (1993). Mapa de Vegetação do Brasil (2a ed., Escala 1:5.000.000). Rio de Janeiro: IBGE.

Instituto Brasileiro de Geografia e Estatística - IBGE. (2016). Cidades. Rio de Janeiro: IBGE. Recuperado em 5 de janeiro de 2017, de http://cidades.ibge.gov.br/v3/ cidades/municipio/3515509

Lucas, R. P. (2008). O código florestal em meio urbano: implicações da aplicação da Lei $n$ o 7.803/89 na regularização de assentamentos irregulares em grandes cidades (Dissertação de mestrado). Faculdade de Arquitetura e Urbanismo, Universidade de São Paulo, São Paulo.

Meneguetti, K. S. (2007). De cidade-jardim a cidade sustentável: potencialidades para uma estrutura ecológica urbana em Maringá-PR (Tese de doutorado). Faculdade de Arquitetura e Urbanismo, Universidade de São Paulo, São Paulo.

Moretti, R. de S. (2005). Recuperação de cursos d'água e terrenos de fundo de vales urbanos: a necessidade de uma ação integrada. Bioikos, 19(1/2), 17-21. 
Porath, S. L., \& Afonso, S. (2006). A Paisagem do Rio Itajaí-Açu na Cidade de Blumenau-SC. In: Costa, L. M. S. A. (Ed.). Rios e Paisagens Urbanas (pp. 163-176). Rio de Janeiro: Viana \& Mosley Editora/Editora PROURB.

Rolnik, R. (1999). Exclusão territorial e violência. São Paulo em Perspectiva, 13(4), 100-111.

Ross, J. L. S., \& Moroz, I. C. (1997). Mapa Geomorfológico do Estado de São Paulo (2 v., 64 p., Escala 1:500.000). São Paulo: FFLCH; USP; IPT; FAPESP.

Sistema Nacional de Pesquisa de Custos e Índices da Construção Civil - SINAPI (2010). Downloads. Recuperado em 30 de outubro de 2010, de http://www.caixa.gov.br/ site/Paginas/downloads.aspx\#categoria_664

Travassos, L. R. F. C. (2010). Revelando os rios: Novos paradigmas para a intervenção em fundos de vale urbanos na cidade de São Paulo (Tese de doutorado). Faculdade de Arquitetura e Urbanismo, Universidade de São Paulo, São Paulo.

Tucci, C. E. M. (2003). Drenagem urbana sustentável no Brasil: estudo de caso de Porto Alegre (Relatório do Workshop em Goiânia-GO). Goiânia: Escola de Engenharia Civil, Universidade Federal de Goiás.

Tucci, C. E. M. (2005). Programa de drenagem sustentável: apoio ao desenvolvimento do manejo das águas pluviais urbanas - versão 2.0. Brasília: Ministério das Cidades.

Tucci, C. E. M. (2006). Curso de Avaliação ambiental integrada de bacia hidrográfica. Brasília: MMA; SQA.

Tucci, C. E. M. (2008). Águas urbanas. Estudos Avançados, 22(63), 97-112.

Recebido: Fev. 10, 2017

Aprovado: Out. 31, 2017 